\title{
Ampliação dos impactos socioambientais negativos da legislação urbanística de Santos/SP
}

\author{
Rafael Paulo Ambrosio, \\ José Marques Carriço*
}

\begin{abstract}
Resumo A norma de uso e ocupação do solo na área insular Santos/SP, aprovada em 2018, alterou significativamente os índices urbanísticos, tornando ainda mais permissiva a produção imobiliária local, moldada pela longa incidência de zoneamento funcionalista, que criou um padrão de ocupação marcado por verticalização dispersa, segregação socioespacial, esvaziamento da área central e impactos negativos no ambiente e na mobilidade urbana. A partir de análise comparativa, este trabalho buscou demonstrar que o novo ordenamento reforça antigas tendências, ampliando potencial construtivo em áreas de interesse do mercado imobiliário, elevando impactos socioambientais negativos em detrimento de um padrão de ocupação sustentável e inclusivo.
\end{abstract}

Palavras-chave: uso e ocupação do solo, mercado imobiliário, Santos/SP.

\section{Aumento de los impactos socioambien- tales negativos de la legislación de plani- ficación urbana de Santos/SP}

\footnotetext{
Resumen La norma del uso y ocupación de la tierra en el área de la isla donde esta ubicada la ciudad de Santos/SP, aprobada en 2018, alteró significativamente los índices urbanos, haciendo que sea aún más permisiva la producción inmobiliaria local, ya moldada por la larga incidencia de la zonificación funcionalista, que creó un estándar de ocupación marcado por verticalización dispersa, segregación socioespacial, vaciamento del área central e impactos negativos sobre el medio ambiente y la movilidad urbana. Basado en un análisis comparativo, este trabajo buscó demostrar que el nuevo orden refuerza las viejas tendencias, expandiendo el potencial constructivo en áreas de interés para el mercado inmobiliario, aumentando los impactos socioambientales negativos en detrimento de un patrón de ocupación sostenible e inclusivo.
}

Palabras clave: uso y ocupación de la tierra, mercado inmobiliario, Santos/SP.

\section{Increase in the negative socio-environmental impacts of urban planning legislation of Santos/SP}

\begin{abstract}
The land use and occupation act of the island area of Santos/SP, approved in 2018, significantly changed the urban indexes, making the real estate production in that area even more permissive, already shaped by the long incidence of functionalist zoning, which created a pattern of land occupation marked by dispersed verticalization, socio-spatial segregation, emptying of the central area and negative impacts on the environment and urban mobility. Thus, from a comparative analysis, this paper aimed to demonstrate that the new law reinforces old trends, expanding the construction potential in areas where the real estate market prefers to produce, increasing negative social and environmental impacts, in detriment of a sustainable and inclusive land occupation pattern.
\end{abstract}

Keywords: land use and occupation, real state, Santos/SP. 
0

art. 23 da Constituição Federal do Brasil (CF) outorgou aos municípios, juntamente com União e Estados, competência para realizar ações que objetivem a proteção ambiental tanto do ambiente natural, quanto do construído, contemplando a proteção de bens de valor histórico, artístico ou cultural, monumentos e sítios arqueológicos, assim como o combate à poluição em qualquer de suas formas.

Em seu art. 30, inciso VIII, a CF outorga exclusivamente aos municípios, a responsabilidade de promover o adequado ordenamento territorial mediante planejamento e controle do uso, do parcelamento e da ocupação do solo urbano. E em seu art. 182, declara que a politica de desenvolvimento urbano a ser executada pelos municípios, objetiva ordenar o pleno desenvolvimento das funções sociais da cidade e garantir o bem-estar de seus habitantes e definindo o Plano Diretor como instrumento básico da politica de desenvolvimento e da expansão urbana, e definidor das exigências fundamentais da ordenação da cidade, voltadas ao cumprimento da função social da propriedade urbana.

Pode-se considerar que o Plano Diretor é o instrumento guia para que a Política Urbana seja implementada, visando construir e ordenar um meio ambiente equilibrado e saudável e a qualidade do meio ambiente urbano depende da convergência entre a qualidade do meio ambiente natural e do meio ambiente construído. E a qualidade de vida das pessoas é garantida pelo cumprimento das funções sociais da cidade e da propriedade, diretamente ligadas à qualidade do espaço urbano produzido. (SILVA, 2010)

A promulgação da Lei Federal n 10.257/2001, Estatuto da Cidade (EC), consolidou o conceito de cidades sustentáveis, entendidas como o direito à terra urbana, à moradia, ao saneamento ambiental, à infraestrutura urbana, ao transporte e aos serviços públicos, ao trabalho e ao lazer para presentes e futuras gerações (art. $\left.2^{\circ}, \mathrm{I}\right)$. O EC definiu como diretriz geral que o planejamento das cidades, a distribuição espacial da população e das atividades econômicas devem atuar, para evitar ou corrigir distorções do crescimento urbano e seus efeitos negativos sobre o meio ambiente. O EC cunhou a expressão "ordem urbanística" (arts 53 e 54) que, segundo Freitas (2004), abrange planejamento, política do solo, urbanização, volumetria das edificações, racionalização

* Rafael Paulo Ambrosio é Arquiteto e Urbanista, Professor do Curso de Arquitetura e Urbanismo da Universidade Católica de Santos, ORCID <https://orcid. org/0000-0003-2858-504x>. José Marques Carriço é Arquiteto e Urbanista, Professor do Programa de Pós-graduação Stricto Sensu em Direito Ambiental e Internacional e pelo Curso de Arquitetura e Urbanismo da Universidade Católica de Santos, ORCID <https://orcid.org/00000002-2249-5409>. do traçado urbano, bom funcionamento dos serviços públicos, correta distribuição da concentração demográfica, criteriosa utilização das áreas públicas urbanas e localização das atividades humanas pelo território. O foco da ordem urbanística é viabilizar o conforto da coletividade, mantendo o equilíbrio entre densidade residencial e ambiente. Tem-se, portanto, que o sistema de normas e institutos trazidos pelo EC, cujo cerne é a ordem urbanística, fez nascer o Direito Urbano-Ambiental, que possibilitou a construção do conceito de cidades sustentáveis. (PRESTES, 2006).

A partir desta perspectiva, busca-se analisar as principais normas urbanísticas do Município de Santos, polo da Região Metropolitana da Baixada Santista (RMBS), em especial quanto aos seus impactos na sustentabilidade do ambiente urbano. 
Santos é sede do maior porto do Brasil e possui tradição de planejamento urbano que remonta ao fim do século XIX. Como exposto em Carriço (2002), essa tradição foi marcada pela aplicação do zoneamento funcionalista, aprofundado na segunda metade do século XX, com a aprovação do Plano Diretor Físico, Lei n 3.529/1968, e sua alteração pela Lei Complementar (LC) n 312/1998, substituída, em 2011, pela LC no 730. Este zoneamento incidiu sobre a área do Município situada na llha de São Vicente, que abrange $39 \mathrm{~km}^{2}$ e onde residem cerca de $99 \%$ da população santista, com alta disparidade de qualidade de vida entre bairros próximos à orla marítima e a precariedade de cortiços na área central, assentamentos no maciço central de morros e palafitas às margens do estuário.

O zoneamento funcionalista contribuiu para moldar um padrão de ocupação do solo marcado por verticalização dispersa, segregação socioespacial, esvaziamento da área central e congestionamento pelo uso excessivo de modos passivos de deslocamento. Segundo Carriço (2002), a sucessão de normas urbanísticas configurou, na área insular, setores com melhor qualidade ambiental junto à orla marítima, em contraposição a áreas cujo processo de urbanização é incompleto ou absolutamente precário,

Durante todo o século XX, a incidência de parâmetros de uso do solo menos permissivos delineou os espaços mais valorizados, nos bairros da orla, já bastante atrativos devido à proximidade do mar. Concomitantemente, pressões do setor imobiliário resultaram em mudanças nos índices de ocupação, sobretudo em períodos de crise de demanda, viabilizando a verticalização e adensamento nesses mesmos bairros, garantindo melhor margem dos empreendimentos (CARRIÇO, 2012).

Em Santos, nos processos de revisão do ordenamento urbanístico, a correlação de forças políticas quase sempre favoreceu o setor imobiliário. No início do século XX, esse setor era composto por loteadores responsáveis pela ocupação da planície marinha entre o centro e a orla, que impediram a implantação do plano urbanístico de Saturnino de Brito, em face do risco ao maior aproveitamento das glebas. Em meio à crise econômica dos anos 1980, o setor imobiliário local pressionou pela mudança

1 Índice que estabelece o número de vezes em que a área de um lote pode ser reproduzida, em forma de área construída. do cálculo do coeficiente de aproveitamento (CA $)^{1}$ dos lotes, e com a sanção da Lei n 174/1986, que alterou o Plano Diretor Físico, para o cálculo do CA deixaram de ser computadas determinadas partes dos condomínios, como áreas comuns e garagens. Assim, na prática os empreendimentos conseguem atingir CA bruto acima de 10 . Durante os anos 1990, em meio a outra etapa da crise econômica, o mesmo setor, com hegemonia na Câmara Municipal, impediu a revisão do Plano Diretor, quando governos progressistas pretendiam regulamentar o artigo 182 da Constituição Federal, até que, em 1998, durante um governo conservador, foi aprovada a Lei Complementar $n^{\circ} 312 / 1998$, que ampliou substancialmente o potencial construtivo dos lotes, entre a área intermediária e a orla, eliminando a restrição de altura das edificações e alterando índices. No processo de revisão que resultou na aprovação da legislação em vigor, objeto deste trabalho, não foi diferente, pois a crise económica atual deu argumentos ao setor imobiliário visando ampliar o potencial construtivo.

Na década passada, impulsionada pelo crescimento econômico nacional e viabilizada pela LC n 312/1998, a produção de torres residenciais de grandes dimensões, com vários pavimentos de garagens e alta oferta de áreas comuns, configurou um padrão de lançamentos imobiliários cuja comercialização foi bastante seletiva em termos de 
2 Esta norma incentivou a produção de "edifícios verdes e inteligentes" em troca de maior potencial construtivo, tendo como consequência a produção de maior número de vagas de automóveis, o que anulou parte dos ganhos ambientais, ao induzir maior uso de modo motorizado de deslocamento.

\footnotetext{
3 Conforme a American Society of Planning Officials (1958), esses índices foram introduzidos no início do século XX, nos primeiros zoneamentos de Nova lorque e Chicago, buscando-se enfrentar os efeitos danosos da altura excessiva dos edifícios, por meio do controle da massa das edificações, disciplinado a relação entre área do lote e área construída (coeficiente de aproveitamento), afastamento da edificação em relação às divisas dos lotes (recuo) e proporção da ocupação do lote pela projeção ortogonal da edificação no nível do solo (taxa de ocupação).
}

renda familiar. Essa modalidade, generalizada em toda a orla e em setores dos bairros localizados entre esta e o centro, produziu impactos relevantes à paisagem e meio ambiente urbanos.

Segundo os censos demográficos do IBGE, desde os anos 1980, Santos apresenta estagnação do crescimento demográfico, em grande parte devido à contínua expulsão e não retenção das famílias com rendas média e baixa, devido ao alto custo dos imóveis, cujo padrão foi moldado pela contínua aplicação das referidas normas urbanísticas (SECOVI, 2019; FARIAS, 2018; CARRIÇO, 2012).

A LC n 730/2011 revogou a LC n 312/1998, introduzindo algumas restrições a este padrão construtivo, limitando-o a vias com maior capacidade e estimulando, ainda que de forma discutível ${ }^{2}$, a produção de edifícios com inovações nos campos de eficiência energética, automação e infraestrutura verde.

Em 2018, a nova norma de ordenamento do uso e da ocupação do solo na área insular, LC n $n^{\circ} 1.006$, revogou a LC $n^{\circ} 730 / 2011$, novamente tornando mais permissiva a produção imobiliária nas áreas preferenciais para o mercado, contraditoriamente com a justificativa de incentivar lançamentos mais acessíveis economicamente.

Portanto, este trabalho busca demonstrar que o novo ordenamento reforça antigas tendências, ampliando significativamente o potencial construtivo em parte da cidade, acarretando previsíveis impactos socioambientais negativos, agravando o padrão acima descrito. Comparando as mencionadas normas urbanísticas, os principais efeitos deletérios deste modelo de produção imobiliária são analisados, considerando aspectos urbanísticos, ambientais e sociais. Em especial, serão destacadas questões relevantes da nova disciplina dos índices urbanísticos, no âmbito da ocupação do solo, privilegiando a análise das mudanças operadas em três índices, cuja aplicabilidade, em termos morfológicos e ambientais, costuma produzir efeitos importantes: coeficiente de aproveitamento máximo, recuos mínimos e taxa de ocupação (TO) máxima ${ }^{3}$.

Desta forma, questiona-se se as alterações dos mencionados índices tornam os imóveis mais acessíveis economicamente e mais sustentáveis ambientalmente, conforme justificativa apresentada no processo de revisão da norma, ou se de fato garantem ao mercado da incorporação residencial maiores margens de lucro, produzindo imóveis longe do alcance da maior parte das famílias, com externalizações ambientais ainda maiores. Os resultados adiante apresentados, por meio da avaliação da evolução desses índices, descortinam um quadro preocupante, agravado pela indefinição na política habitacional nacional voltada para famílias de baixa renda.

\section{A justificativa para a mudança da lei e os novos índices}

Desde o Código de Construções de 1922, Lei n 675, o padrão de uso e ocupação do solo na área insular de Santos foi determinado pelo zoneamento funcionalista, com instituição da Zona Comercial na área central, ampliada pelo Decreto-lei n 403 de 1945, que criou uma Zona Comercial Secundária, e o Plano Diretor Físico de 1968, Lei $n^{\circ} 3.529$, que ampliou o zoneamento não residencial até a área intermediária entre o centro e a orla e ao longo de alguns eixos viários. Da esquerda para a direita, na parte inferior da Figura 1, apresenta-se, respectivamente, esses zoneamentos. Na 


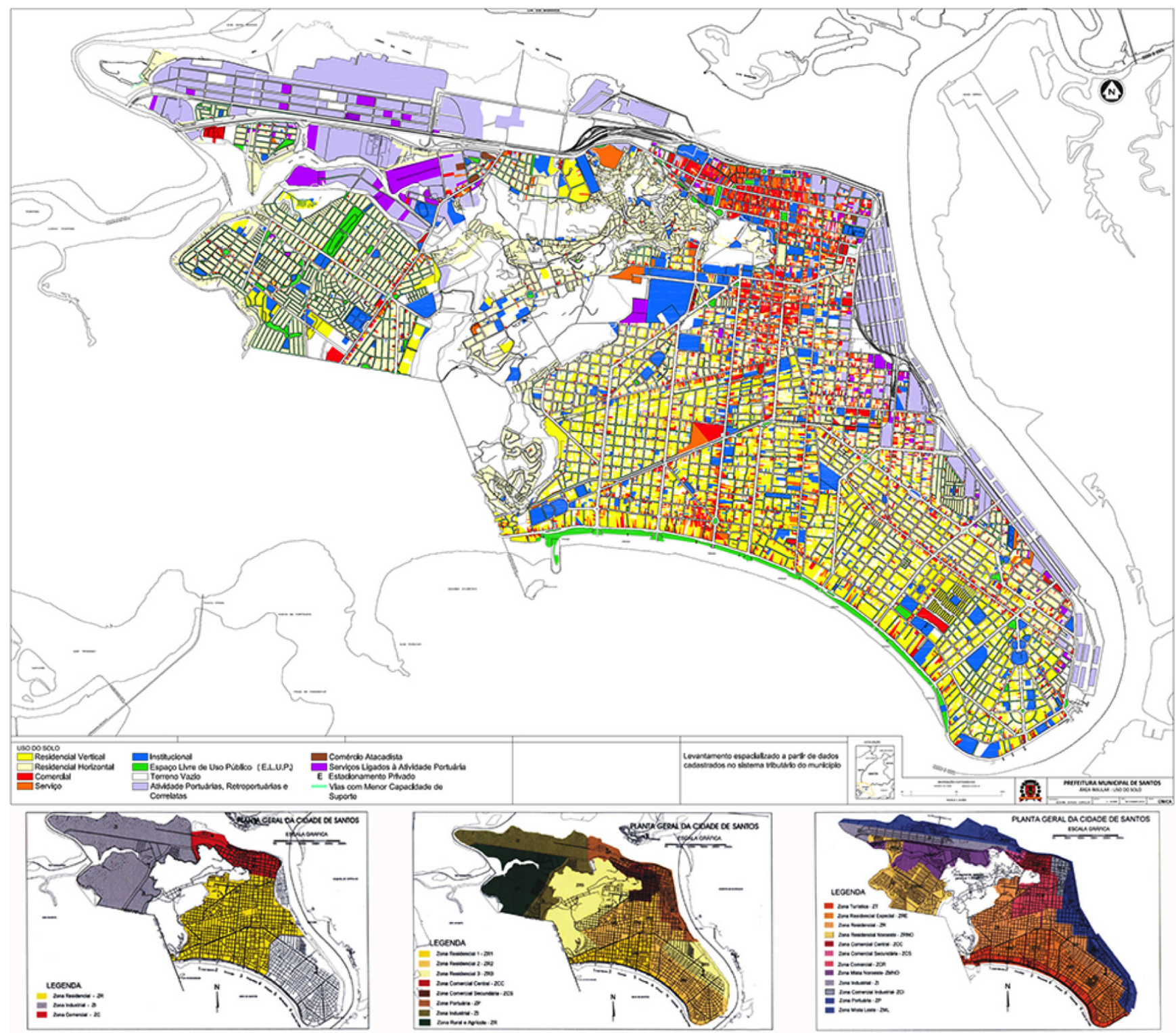

Figura 1: Uso do solo e zoneamentos funcionalistas incidentes durante o século XX. Fonte: Prefeitura Municipal de Santos (2013) e Carriço (2002). parte superior da figura, observa-se o mais recente levantamento de uso do solo da área insular, onde se concentram usos comerciais, entre a área central e a porção intermediária, acompanhando eixos viários, até o subcentro do bairro Gonzaga, na orla. O esvaziamento da área central, como demonstrado em Barros e Carriço (2019), foi consequência, em grande parte, do deslocamento de famílias em direção à orla, em face da concentração de usos mais impactantes na área central, permitidos pelos mencionados zoneamentos.

O levantamento distingue uso residencial horizontal do vertical, respectivamente amarelo claro e escuro, permitindo observar o esvaziamento residencial da área central e a verticalização concentrada entre a orla e a área intermediária da Zona Leste da cidade. 
4 Disciplinada pela portaria DECEA n 29/ICA, de 14 de julho de 2015, em atendimento à portaria n ${ }^{\circ}$ 957/2015, do Comando da Aeronáutica (COMAER).

Figura 2: Produção Imobiliária e Zona de Proteção de Aeródromo da Base Aérea de Santos.Fonte: Elaborado com base nas portarias n 957/2015 e DECEA n²9/ICA, do COMAER; Zoneamento da Lei Complementar $n^{\circ}$ 1.006/2018 e dados do SECOVI (2019).
Conforme Carriço (2012), esta verticalização se relaciona com a renda, pois famílias com maiores rendimentos se concentram preponderantemente nas áreas mais verticalizadas. Enquanto isso, a Zona Noroeste, à esquerda no mapa, concentra usos portuários ao norte, e uso residencial horizontal, com baixa oferta de comércio e serviços, ao sul. 0 desequilíbrio provocado pela incidência desse zoneamento provoca deseconomias, pois a ociosa área central apresenta oportunidades de trabalho, bons serviços e infraestrutura, enquanto pendularidades se formaram entre orla, Zona Noroeste e área central, como observado na Pesquisa Origem e Destino da Baixada Santista (EMTU, 2013).

Desde os anos 1970, conforme FARIAS (2019) e CARRIÇO (2002), esse desequilíbrio foi agravado pela migração de famílias de menor renda, do polo para municípios da área metropolitana, e redução drástica da migração em direção ao polo, resultando em clivagem socioespacial, marcada pela estagnação da população do município e formação de novas pendularidades (EMTU, 2013), pois este concentrava 49\% dos postos de trabalho regionais (IBGE, 2010). Hoje, o principal vetor de migração interna da Baixada Santista é Praia Grande, que segundo SECOVI (2019), entre 2016 e 2019, ofertava unidades de 2 dormitórios com $62 \%$ do preço médio praticado em Santos.

Assim, desde 2013, com aprovação da LC n 821, Plano Diretor anteriormente vigente, discutia-se estratégias para enfrentar esses desequilíbrios e repovoar a área central. Contudo, a regulamentação do plano estendeu-se até 2018, quando este foi revogado pela LC n 1.005/2018, o Plano Diretor atual, que manteve as mesmas diretrizes de repovoamento do centro, com estratégias regulamentadas pela LC $n^{\circ} 1.006 / 2018$, Lei de Uso e Ocupação do Solo na Área Insular, que alterou os índices urbanísticos. A justificativa que embasou a revisão dos índices (SANTOS, 2018), foi a necessidade de ampliar o potencial construtivo na área da cidade mais afetada por restrições à Zona de Proteção de Aeródromo (ZPA) da Base Aérea de Santos, cujos perímetros de cônicas e planos imaginários estão em vermelho e azul na Figura 2. A área mais afetada pela ZPA está hachurada de vermelho, com limite de altura de 45,0 m para

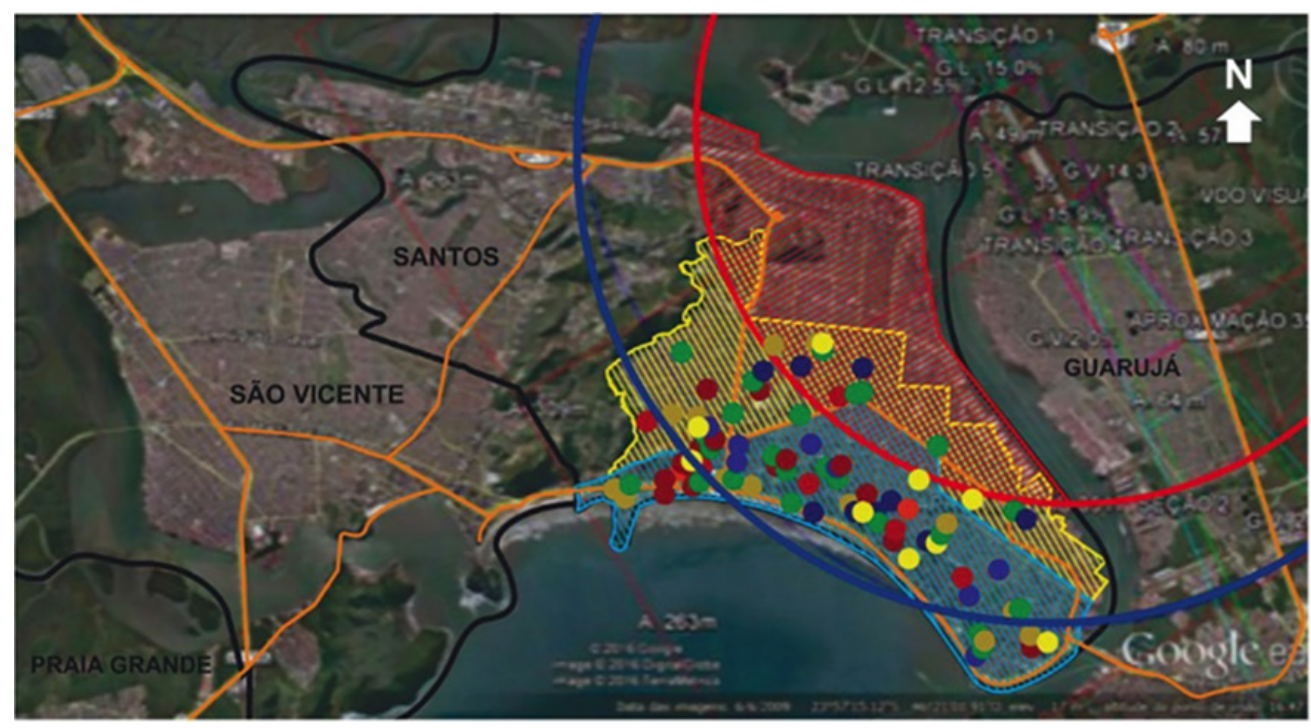

\section{LEGENDA}

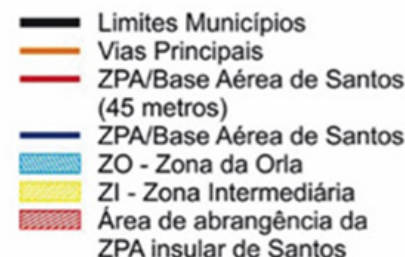

Empreendimentos Lançados

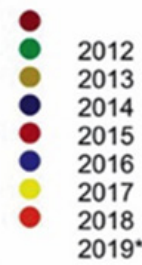


5 Descontadas as áreas construídas não computáveis estabelecidas pela lei (art. 53)

\footnotetext{
6 Esta dispensa baseia-se na premissa de que a zona denominada Área de Adensamento Sustentável Norte (AAS-N) deve ser atendida em breve pela extensão do trajeto do Veículo Leve sobre Trilhos (VLT), antes prevista para 2020.
}

\footnotetext{
7 Método de planejamento que visa promover o adensamento habitacional ao longo dos eixos de transporte de massa ou de média capacidade, o que faz bastante sentido, em termos de mobilidade urbana, no tocante ao VLT implantado em Santos.

8 Segundo o art. 50 do novo Plano Diretor, LC n 1.005/2018, as AAS compreendem as áreas ao longo dos sistemas de transporte coletivo de média capacidade de carregamento existentes e previstos na Macroárea Insular, que serão delimitadas na Lei de Uso do Solo. [grifo dos autores]
}

quaisquer objetos a serem edificados, abrangendo cerca de $28 \%$ da área insular e incluindo toda a área central.

A ampliação do potencial viabilizaria novos empreendimentos na área mais afetada pelas restrições de altura, que abrange também parte da Zona Leste mais próxima ao Porto, ao norte da área hachurada em amarelo, que corresponde à Zona Intermediária (ZI) delimitada pela LC 1.006/2018. Assim seria mitigado possível aumento do preço dos imóveis resultante do menor aproveitamento dos terrenos. Contudo, como demonstra a figura, poucos empreendimentos foram lançados nesta área e ainda assim na ZI, segunda zona preferencial das incorporadoras, revelando a ineficácia da estratégia, atestada pela declaração de representante do mercado imobiliário local: "a conta não fecha" para empreendimentos em bairros pericentrais, na área de maior restrição de altura das edificações (SANTOS, 2019).

Na verdade, o pano de fundo da revisão da norma foi a crise econômica iniciada em 2014, que praticamente paralisou o mercado imobiliário da cidade (SECOVI, 2019) e provocou desemprego na construção civil e desvalorização dos imóveis na área central.

Mas a LC n 1.006/2018 ampliou o potencial construtivo em área bem maior que a central, compreendendo a Zona da Orla (ZO) e a parte da ZI sem a restrição de 45,0 $\mathrm{m}$, as mais valorizadas da cidade. Conforme a Figura 2, todos os empreendimentos lançados até 2019 localizam-se nessas zonas, contrariando a justificativa para ampliação dos índices urbanísticos.

Santos (2018) não apresentou estudos que comprovassem que a ampliação de potencial construtivo tornaria mais atrativa a área afetada pela restrição. Mas, de acordo com estudos da Prefeitura, realizados entre 2013 e 2016, o limite de 45,0 m não comprometeria o alcance do coeficiente de aproveitamento (CA) líquido ${ }^{5}$ igual a 6 nessa área, mesmo com recuos mínimos e TO máxima em vigor anteriormente. Na verdade, havia possibilidade de se praticar este CA, limitando-se a oferta de áreas comuns nos condomínios e reduzindo a exigência de número mínimo de vagas para automóveis, o que não é previsto de forma satisfatória na nova lei ${ }^{6}$. O excesso de áreas comuns e de vagas, costumeiramente ofertadas nos empreendimentos imobiliários lançados em Santos, encarece o valor final da unidade, tornando-a menos acessível para famílias de rendas baixa e média (SHOULP, 2017).

Outra estratégia da LC n 1.006/2018 foi a regulamentação de uma política de Desenvolvimento Orientado pelo Transporte $(\mathrm{DOT})^{7}$, já prevista no Plano Diretor de 2013, que delimitou as Áreas de Adensamento Sustentável (AAS) ${ }^{8}$ em vias já saturadas, como avenidas Conselheiro Nébias, Pedro Lessa e Nossa Senhora de Fátima, sendo esta última suscetível a alagamentos. Porém não há perspectiva de implantação de transporte de média capacidade a médio prazo, pois a segunda fase do VLT, que se estenderá até o centro, tem seu calendário muito atrasado. Portanto, a LC $n^{\circ}$ 1.006/2018 incentiva adensamento em áreas ainda não servidas pelo VLT, o que poderá agravar a mobilidade urbana.

A partir da análise comparativa dos principais índices urbanísticos, nas seções seguintes evidencia-se que o objetivo principal da revisão foi a ampliação do potencial construtivo nas áreas preferenciais de atuação do mercado imobiliário, ZO e ZI, onde o potencial construtivo já era extremamente elevado, resultando na ampliação da margem de 
9 O CAMáx, novidade da norma, é o CA permitido além do CA Básico (CAB), mediante cobrança de Outorga Onerosa do Direito de Construir (OODC), instrumento de política urbana criado pelo EC, para permitir que os municípios recuperem parcialmente a mais valia fundiária decorrente de investimentos públicos e privados na área de determinado empreendimento. As VMCS, estabelecidas no Anexo VI e no mapa do Anexo VIII, são, em geral, mais estreitas, demandando limitação do porte das edificações, sendo as demais vias consideradas normais. O CAA, outra inovação, permite edificar acima do CAMáx, satisfeitas determinadas exigências.

$100 \mathrm{Fp}$ multiplica a fórmula de cálculo da OODC.

11 CDUs são "vias que possuem grande capacidade de circulação, onde se pretende estimular 0 adensamento sustentável" (inciso IV, art. 14 e mapa do Anexo VIII). [grifo dos autores]

12 Norma que regulamentou os instrumentos do EC e foi revogada pela LC 1.006/2018.

Tabela 1:Evolução do CA nas zonas de interesse do mercado imobiliário entre 1968 e 2018. Fonte: Lei $n^{\circ} 3529 / 1968, L C n^{\circ}$ 312/1998, LC n 730/2011 e LC $n^{\circ} 1.006 / 2018$. lucro, de forma a contrabalançar o efeito da redução dos lançamentos decorrente da crise, ao contrário do discurso oficial, que justificava a ampliação dos índices como estratégia para ativar a produção imobiliária na área central de Santos.

\section{Coeficiente de Aproveitamento (CA)}

A LC 1.006/2018 ampliou o potencial construtivo nas localizações preferenciais do setor imobiliário, amparada na justificativa acima exposta, como compensação às restrições das portarias do COMAER além da oferta de questionáveis benefícios urbanísticos. Para melhor compreensão, a Tabela 1 apresenta a evolução do CA, desde seu surgimento no Plano Diretor de 1968, até o presente.

Neste caso enquadra-se a criação das "Áreas de Integração" (Al), instrumento inédito definido no inciso VIII, do art. $4^{\circ}$, da LC 1.006/2018. De acordo com os artigos 58 e 64, respectivamente, nas ZO e ZI, é possível edificar com Coeficiente de Aproveitamento Máximo (CAMáx) igual a 5, nas "vias de menor capacidade de suporte" (VMCS), ou com o Coeficiente de Aproveitamento Ampliado (CAA) igual a 6, nas vias normais, adotando-se a "Área de Integração", juntamente com a aplicação de OODC 9 , cujo cálculo prevê a multiplicação do valor apurado por um "Fator de Planejamento" (Fp) igual a 0,410, resultando em contrapartida de pequeno valor (art. 154). Assim, a contrapartida prevista será de apenas $40 \%$ do valor, nas ZO e ZI, quando se quiser alcançar o CAMáx. Mas nessas zonas a diferença entre CAB e CAMáx é de apenas um ponto: 5 contra 6, nas vias normais e 4 contra 5, nas VMCS. Portanto, esse cálculo da contrapartida resulta em valor modesto para o alcance de CAMáx, e ainda menor para adoção do CAA, em face do potencial construtivo adicional.

Além disso, nas ZO e ZI, respectivamente arts. 59 e 65, nos Corredores de Desenvolvimento Urbano (CDU) ${ }^{11}$, poderá ser edificado até o CAA igual a 6 , mediante oferta de Al de $40 \%$ no recuo frontal e OODC, com Fp igual a 0,2, equivalendo a $10 \%$ do estabelecido na LC $n^{\circ} 551 / 2005^{12}$. Portanto, nessas vias, a contrapartida é ainda menor e a ampliação do CA é maior, sem que haja embasamento técnico para essa alteração, pois, com exceção da Av. Francisco Glicério, por onde já circula o VLT, foram classificadas como CDU vias já saturadas, onde o acréscimo de adensamento impactará ainda mais o trânsito.

\begin{tabular}{|c|c|c|c|c|}
\hline Norma & Zona & CA/CAB & CA Máximo & CA Ampliado \\
\hline Lei $3529 / 1968^{(1)}$ & $Z R^{(2)}$ & 4 & N/A & N/A \\
\hline LC 312/1998 & $\mathrm{ZO} \mathrm{e} \mathrm{ZI}$ & 5 & $\mathrm{~N} / \mathrm{A}$ & $\mathrm{N} / \mathrm{A}$ \\
\hline LC 730/2011 & ZO e ZI & 4 ou $5^{(3)}$ & 6 & $\mathrm{~N} / \mathrm{A}$ \\
\hline LC 1.006/2018 & ZO e ZI & $4^{(4)}$ & 5 & 6 \\
\hline
\end{tabular}

(1) Em 1986 foi alterado o cálculo do CA de forma a não computar determinadas áreas condominiais.

(2) As atuais ZO e ZI equivalem à Zona Residencial (ZR), com diferenças de perímetro. Esta zona foi subdividida em ZR e Zona Residencial Especial (ZRE), pela Lei n²09/1986.

(3) O CA era 4 nas vias mais estreitas, denominadas "vias com menor capacidade de suporte", e 5 nas demais.

(4) Foi instituído formalmente o CA Básico (CAB). N/A - Não se aplica pois não existia. 


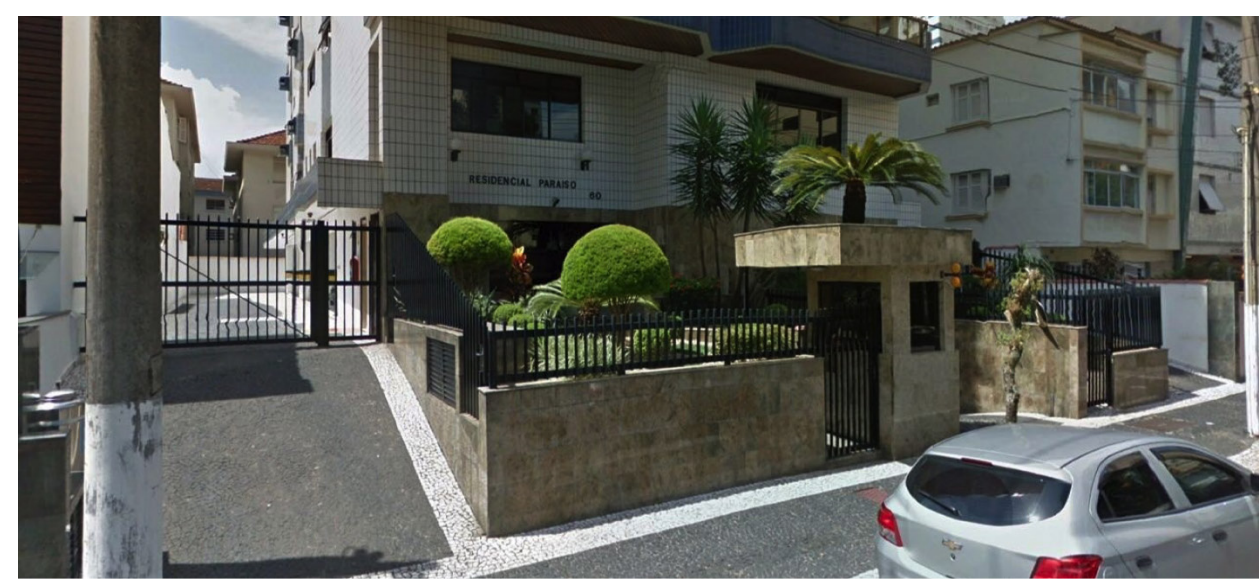

Figura 3: Testada de lote na ZO, com mais de $40 \%$ da extensão sem fechamento. Fonte: Google Street View (2018).

${ }_{13}$ Altura que a face superior da laje de cobertura do subsolo pode atingir, com relação ao nível do meio fio.

14 Os CDRUs eram equivalentes aos CDUs vigentes. Contudo, a relação das vias classificadas como CDU teve inclusões, como a Av. Bernardino de Campos e trecho da Av. Epitácio Pessoa, e exclusão da Av. Washington Luís e rua Euclides da Cunha, a maior parte das quais bastante saturadas.
Os benefícios urbanísticos da Al são questionáveis. Com promessa de garantir o não fechamento de parte da área frontal dos lotes para maior integração entre espaços público e privado, a norma considera satisfatório, mesmo quando a frente do lote possui a elevação de até 1,4 m acima do nível da via, em virtude do afloramento do subsolo ${ }^{13}$, barreira à verdadeira integração, diferindo pouco ou nada do que já é praticado atualmente. Conforme Figura 3, em empreendimentos preexistentes, com mera implantação de rampas de acesso de veículos na frente dos edifícios, não consideradas como fechamento pela nova lei, já se atinge os $40 \%$ do recuo frontal, sem grade ou muro e sem que haja verdadeira integração. Portanto, esse pretenso benefício urbanístico em troca de maior potencial construtivo favorecerá apenas os incorporadores. Se o uso de subsolo aflorado e rampas de acesso de veículos fossem limitadas no recuo frontal, onde suprimem a arborização urbana, a elevação do CA com contrapartida reduzida poderia trazer algum benefício.

Pela LC $n^{\circ}$ 730/2011, nas ZO e ZI só era possível atingir CA igual a 5 e 4, respectivamente, nas vias normais e VMCS, posto que não existiam CAMáx e CAA. Naquela norma, somente nos "Corredores de Desenvolvimento e Renovação Urbana" (CDRU) ${ }^{14}$ era possível alcançar o CA igual a 6. Assim, devido aos novos critérios de utilização do CA, tende-se ao agravamento de problemas de trânsito, insolação e ventilação naturais nas áreas mais adensadas do Município, sem que os recursos da OODC possibilitem financiar adequadamente medidas mitigadoras desses impactos ambientais nocivos decorrentes do maior potencial construtivo.

É grande a quantidade de vias não enquadradas como de "menor capacidade de suporte" na ZO e ZI, onde, na prática, o CAMáx será o CAA, dada a enorme facilidade para adotá-lo. Nessas zonas, os impactos com adensamento construtivo serão maiores, com evidentes prejuízos ambientais e urbanísticos, pois será possível ultrapassar coeficientes brutos de cerca de 12 vezes a área dos lotes.

Na norma vigente, ampliou-se o incentivo à construção de terraços, terraços técnicos e varandas, pois na anterior (art. 29), no cálculo do CA, só eram computadas as áreas 
15 Segundo a LC 1.006/2018 (art. 154, IV, § único), o Fp é "variável por zona, via ou condicionantes especiais".
Tabela 2. Coeficientes de Aproveitamento por zona, de acordo com a LC no 1.006/2018. Fonte: elaborada a partir dos CAs estabelecidos no Capítulo III - Das Diferenças Zonais. N/A = Não de aplica à zona. desses elementos acima de 1/3 "da somatória das áreas de todos os compartimentos destinados a salas, dormitórios e suítes com suas dependências" e nem eram desconsiderados os terraços técnicos. Na LC n 1.006/2018 (inciso II, art. 53), essas áreas não serão computadas, quando possuírem área inferior ou igual a $30 \%$ "da área interna da unidade privativa".

Quanto à OODC, é importante observar como fica o cálculo da contrapartida na nova norma. Anteriormente ( $\left.L C n^{\circ} 551 / 2005\right)$, a fórmula era $C \geq A a x(2 x \mathrm{Vt})$, sendo "C" a contrapartida financeira, "Aa" a área adicional outorgada e "Vt" o valor unitário atual de terreno para cálculo do valor venal dos imóveis. A nova fórmula (art. 156 da LC $n^{0}$ 1.006/2018) é C $=A a \times V t \times F p^{15}$, que aplicada em vários pontos da lei, reduz a contrapartida, pois o Vt anteriormente era dobrado. Assim, a contrapartida diminui nas ZO e ZI (arts. 58, 64, 65 e 66), ao se multiplicar, respectivamente, "Aa" por "Fp" de 0,4 e 0,2, para autorizar, mediante a oferta da "Área de Integração", a ampliação do CA de 4 para 5, nas VMCS, e de 5 para 6, em vias normais. Portanto, a contrapartida resultante será equivalente a $10 \%$ e $20 \%$, respectivamente, do praticado anteriormente em vias normais e VMCS.

Ressalta-se a falta de fundamento urbanístico para OODC em VMCS, que, em geral, não possuem condições para receber maior adensamento. Em troca de "benefícios" discutíveis, essas vias serão sobrecarregadas e a "Área de Integração" eliminará um dos poucos avanços ambientais trazidos pela LC $n^{\circ} 730 / 2011$, com relação à LC $n^{\circ}$ $312 / 1998$.

Na Tabela 2 apresenta-se a variação do CA por zona, observando-se, nas ZO e ZI, pequena diferença entre CAB e CAMáx, igual a 1, e entre CAB e CAA, igual a 2. Contraditoriamente, nessas zonas onde é menor a restrição de altura imposta pelo COMAER, é inferior o valor da OODC, retirando-se atratividade para produzir unidades de menor custo em parte da área central, como na Zona Central II (ZC II), conforme os objetivos da revisão da norma.

Nas Zonas Especiais de Renovação Urbana (ZERU), outra inovação da norma, há diferencial substancial entre CAB e CAMáx, apenas quando delimitadas em parte da área central (arts. 100 a 103), ainda assim admitindo-se que não haja pagamento de contrapartida financeira, para que se atinja o CAMáx, com oferta da Al. Mas é improvável que incorporadores se interessem em produzir nessa área, pois nas ZO e ZI, atinge-se elevado CAA com Al e contrapartida reduzida.

\begin{tabular}{l|l|l|l|l|l|l|l|l|l}
\hline CA/Zona & ZO & ZI & ZCI e II & ZN I, II e III & ZM I, II e III & ZP & ZIR I e II & AAS & ZERU (*) \\
\hline CAMin & 0,5 & 0,5 & 0,5 & 0,5 & 0 & 0,5 & 0,5 & 0,5 & 0,5 \\
\hline CAB & 4 & 4 & 4 & 3 & 2 & 5 & 5 & 4 & 1 \\
\hline CAMáx & 5 & 5 & 6 & 3 & 2 & 5 & 5 & 5 & 7 \\
\hline CAA & 6 & 6 & N/A & N/A & N/A & N/A & N/A & 6 & N/A \\
\hline
\end{tabular}

(*) Na ZERU Jabaquara, os índices urbanísticos aplicáveis são os definidos para a zona normal à qual está sobreposta. 
Esta ampliação de CA nas áreas de interesse do mercado potencializa-se com a possibilidade de praticar menores recuos e maior TO, como será tratado adiante. Portanto, haverá efetiva ampliação do adensamento construtivo, em áreas pouco afetadas pela restrição do COMAER, sem garantia de incentivo à produção de unidades habitacionais mais econômicas.

Este quadro agrava-se com a adoção do CAA. Por exemplo, nas AAS, corretamente, a LC n' 1.006/2018 incentiva a produção de empreendimentos direcionados a famílias de baixa e média-baixa rendas, com oferta de comércio e serviços no pavimento térreo, os quais contarão com isenção de OODC (art. 95). Nessas zonas, a contrapartida com a OODC para empreendimentos dirigidos a rendas mais altas, seria reduzida à metade, com a oferta de comércio e serviços no pavimento térreo, o que também faz sentido, em área onde se quer incentivar vitalidade urbana e gerar empregos. Porém, dificilmente isto será um diferencial, em face da elevada permissividade de índices nas ZO e ZI, onde o tipo de unidade habitacional produzido é quase exclusivamente dirigido a famílias com renda mais elevada, a menor demanda no Município (MEYER, 2008).

As AAS, que poderiam ser indutoras de produção imobiliária voltada a famílias de menor renda, tendem a não funcionar como tal, em função dos índices permissivos nas ZO e ZI, mantendo-se a lógica da produção voltada às famílias de maior renda, em detrimento à oferta de moradia para o restante da população, aumentando a pressão por ocupação de áreas ambientalmente protegidas, com as nefastas consequências da degradação ambiental.

\section{Recuos mínimos e Taxa de Ocupação máxima}

Pérez e Favero (2009) comprovam os impactos ambientais da redução dos recuos, para o caso da preservação da iluminação natural da vizinhança. No tocante à ventilação natural, destaca-se o trabalho de Prata (2005), que analisa o processo de verticalização no bairro Pompeia, na ZO de Santos, evidenciando substancial redução da velocidade dos ventos no interior do bairro, devido à verticalização, em período anterior à aceleração da produção imobiliária na cidade.

16 Bloco inferior dos edifícios, definido na LC n 1.006/2018, como "o volume arquitetônico inferior, constituído por até 05 (cinco) pavimentos, para uso não residencial, utilizado exclusivamente para comércio e serviço, vagas de garagem e/ou atividades comuns do edifício", beneficiado por parâmetros de recuos e taxa de ocupação diferenciados, com relação ao bloco dos pavimentos-tipo.

17 Grupo de estudantes e egressos do Curso de Arquitetura e Urbanismo da Universidade Católica de Santos.

18 Também conhecida como "pé-esquerdo", bastante praticada pelo mercado local.
Assim, nesta seção complementa-se a análise com o estudo da evolução dos recuos mínimos laterais e de fundos e da TO máxima nas ZO e Zl, entre 1968 e 2018, conforme Tabela 3. Junto com a ampliação da TO, a redução desses recuos, que mais impactam a vizinhança dos empreendimentos, contribui para aumentar o potencial construtivo de lotes na ZO e ZI, articuladamente à ampliação do CA.

A LC n 1.006/2018 permite a redução de recuos laterais e de fundos, com relação ao exigido anteriormente, principalmente a partir do $15^{\circ}$ pavimento, incluindo os pavimentos do embasamento ${ }^{16}$, conforme modelagem elaborada pelo Coletivo Urbanize-se ${ }^{17}$ (Figura 4), sob orientação dos autores, por ocasião do processo de revisão da norma. Na figura compara-se a aplicação dos índices da LC n 730/2011 e LC n 1.006/2018, para empreendimento fictício, com 13 pavimentos-tipo e o maior número de pavimentos nos embasamentos, em terreno com 1.000,00 $\mathrm{m}^{2}(20,0 \mathrm{~m} \times 50,0 \mathrm{~m})$.

Segundo esse estudo, tendo como base a distância de 3,06 $\mathrm{m}^{18}$, entre as superfícies superiores de lajes de piso subsequentes, a redução dos recuos pode variar entre $30 \mathrm{~cm}$, no $15^{\circ}$ pavimento, até $2,80 \mathrm{~m}$, no $30^{\circ}$ pavimento, com impactos ambientais nocivos, posto que esta redução está associada à ampliação da TO e provavelmente da altura do edifício. 


\begin{tabular}{|c|c|c|c|c|c|}
\hline Norma & Zona & $\begin{array}{l}\text { Recuo bloco } \\
\text { pav. tipo }\end{array}$ & $\begin{array}{c}\text { Recuo } \\
\text { embasamento }\end{array}$ & $\begin{array}{l}\text { TO torre } \\
(\%)\end{array}$ & $\begin{array}{c}\text { TO embasa- } \\
\text { mento (\%) }\end{array}$ \\
\hline \multirow{2}{*}{$\begin{array}{c}\text { Lei } \\
\text { 3529/1968 }\end{array}$} & \multirow{2}{*}{$Z R^{(1)}$} & $\begin{array}{l}1,5+\mathrm{H} / 10 \text { nas } \\
\text { demais vias }\end{array}$ & N/A & \multirow{2}{*}{50} & \multirow{2}{*}{ N/A } \\
\hline & & $\begin{array}{l}2,0+\mathrm{H} / 10 \text { em via } \\
\text { principal }^{(2)}\end{array}$ & N/A & & \\
\hline $\begin{array}{c}\text { LC } \\
312 / 1998\end{array}$ & ZO e ZI & $1,5+\mathrm{H} / 10$ & $\mathrm{~N} / \mathrm{A}$ & 40 & 60 \\
\hline \multirow{4}{*}{$\begin{array}{c}\text { LC } \\
730 / 2011\end{array}$} & \multirow{4}{*}{ ZO e ZI } & \multirow{4}{*}{$\begin{array}{l}1,50 \mathrm{~m} \text { até o } 3^{\circ} \\
\text { pav. e a partir } \\
\text { deste acrescendo } \\
0,30 \mathrm{~m} \text { por pav. }\end{array}$} & 3,00 m até 4 pav. & \multirow{4}{*}{40} & \multirow{4}{*}{$60^{(4)}$} \\
\hline & & & $\begin{array}{l}\text { 3,00 m até } 3 \text { pav. } \\
\text { sem observar TO }\end{array}$ & & \\
\hline & & & $1,50 \mathrm{~m}$ até 3 pav. & & \\
\hline & & & $\begin{array}{l}\text { 1,50 m até } 2 \text { pav. } \\
\text { sem observar TO }\end{array}$ & & \\
\hline \multirow{3}{*}{$\begin{array}{c}\text { LC } \\
1.006 / 2018\end{array}$} & \multirow{3}{*}{ ZO e ZI } & $\begin{array}{l}\text { H/10 c/ mínimo de } \\
1,50 \mathrm{~m}\end{array}$ & \multirow{3}{*}{$\begin{array}{l}\text { H/6 se adotado } \\
\text { H/15 no bloco } \\
\text { dos pav. tipo }\end{array}$} & \multirow{3}{*}{$50^{(3)}$} & \multirow{3}{*}{$60^{(4)}$} \\
\hline & & $\begin{array}{l}\text { H/12 c/ mínimo de } \\
1,50 \mathrm{~m}\end{array}$ & & & \\
\hline & & $\begin{array}{l}\text { H/15 c/ mínimo de } \\
3,60 \mathrm{~m}\end{array}$ & & & \\
\hline
\end{tabular}

(1) As atuais ZO e ZI equivalem à Zona Residencial (ZR), com diferença de perímetro. Em 1986 esta zona fo subdividida em ZR e Zona Residencial Especial (ZRE), pela Lei nº 209.

(2) Pela Lei $n^{\circ} 174 / 1986$ passaram a 1,50 $\mathrm{m}$ até o $3^{\circ}$ pavimento em qualquer via, acrescendo $0,30 \mathrm{~m}$ por pavimento a partir deste.

(3) $60 \%$ na área de restrição de $45,00 \mathrm{~m}$ de altura, imposta pela portaria do COMAER.

(4) Aplicada nos 4 primeiros pavimentos e dispensada a TO no embasamento quando o recuo for H/6.

Tabela 3: Evolução dos Recuos laterais e de fundos e da TO nas ZO e ZI (1968 a 2018). Fonte: Lei $n^{\circ}$ 3529/1968, LC n' 312/1998, LC $\mathrm{n}^{\circ} 730 / 2011$ e LC n० $1.006 / 2018$ N/A - Não se aplica pois não existia.

Figura 4: Comparação da ocupação do lote entre LC 730/2011 e LC 1.006/2018. Fonte: Coletivo Urbanize-se (2018).

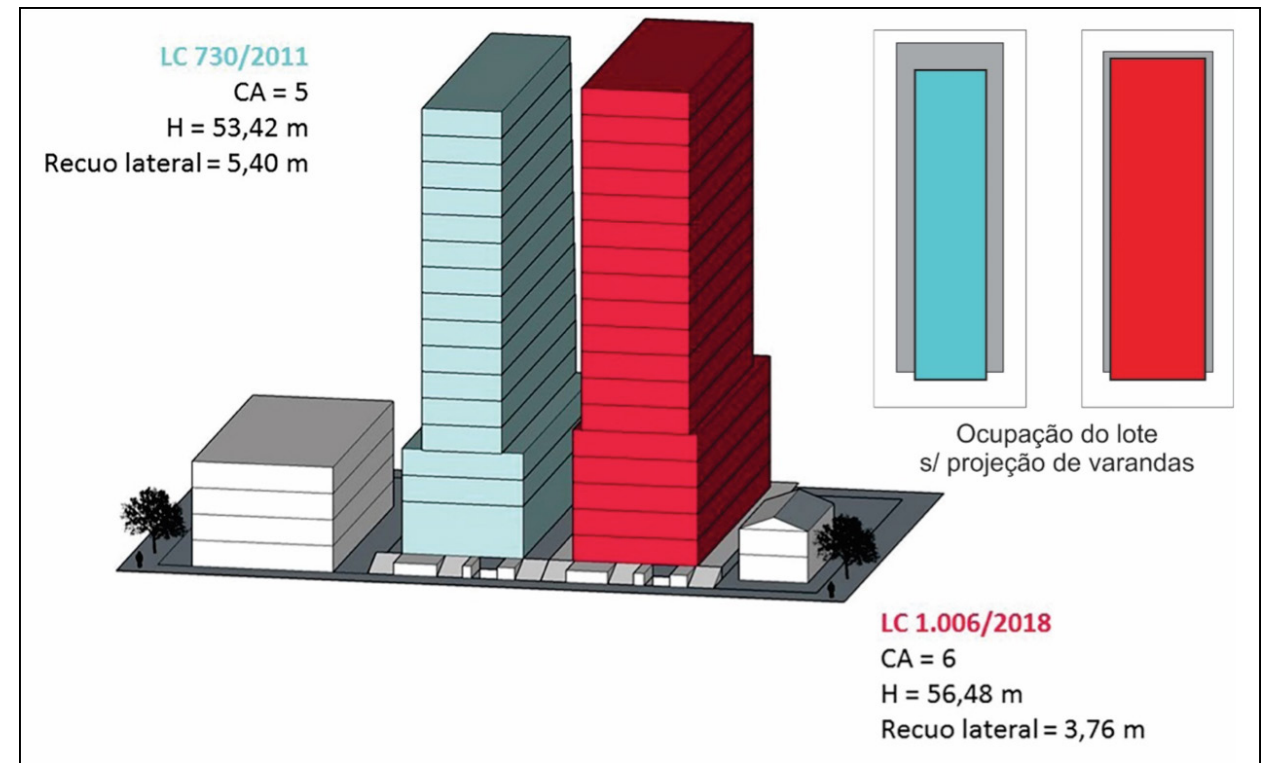


19 Antes havia 4 opções de recuos laterais e de fundos, conforme Tabela 3.

Figura 5. Recuos de embasamento em empreendimento aprovado sob a LC n³12/1998. Fonte: fotografias dos autores (2017 e 2020).
A LC n' 1.006/2018 oferece 3 alternativas de recuos laterais e de fundos, onde " $\mathrm{H}$ " é a altura da edificação medida a partir do meio fio:

- H/10 com mínimo de 1,5 m, para edificações horizontais;

- H/12 com mínimo de 1,5 m para blocos de pavimentos-tipo em edifícios residenciais. Sem menção explícita, esta opção deverá ser utilizada em edifícios sem embasamento;

- H/15 para blocos de pavimentos-tipo em edifícios residenciais, com recuo mínimo de 3,60 m no referido bloco, e se possuírem embasamento com recuo mínimo de $H / 6$, sendo " $\mathrm{H}$ " a altura do embasamento.

Anteriormente, seria possível praticar recuo de $\mathrm{H} / 12$, em edifícios cujos pavimentos possuíssem pés-direitos dos pavimentos-tipo maiores que 3,00 m, o que não era conveniente, pois aumentava o custo da construção. Agora, é possível praticar este recuo sem este ônus.

A escolha da alternativa $\mathrm{H} / 15$, para recuos laterais e de fundos, em função de seus condicionantes, permite embasamentos com recuos laterais iguais ou inferiores aos que eram obrigatórios pelo art. 35 da LC n 730/2011'19. Mas se o "pé-esquerdo" for de 3,06 m, os recuos laterais e de fundos nos embasamentos de até 5 pavimentos serão de $2,78 \mathrm{~m}$ (inciso II, $\S 2^{\circ}$, art. 42) e não será exigida TO para os embasamentos ( $\S 3^{\circ}$ do art. 42). Portanto, os recuos do embasamento poderão ser ainda menores, sem as opções com menos pavimentos nesse bloco, com exigência de TO.

Fica claro que será adotada a alternativa $\mathrm{H} / 15$, pois os recuos não serão maiores e os embasamentos poderão ter até 5 pavimentos e ofertar mais vagas de automóveis, o que encarecerá as unidades e provocará mais impacto no trânsito. Em lotes de tamanho médio, mais usuais em Santos, haverá ganho evidente de potencial construtivo, com prejuízos à iluminação e ventilação naturais de pavimentos mais baixos de edifícios vizinhos, com compartimentos de uso prolongado voltados para os embasamentos, piorando situação já verificada antes (Figura 5), principalmente nas ZO e Zl, onde os impactos ambientais serão generalizados.
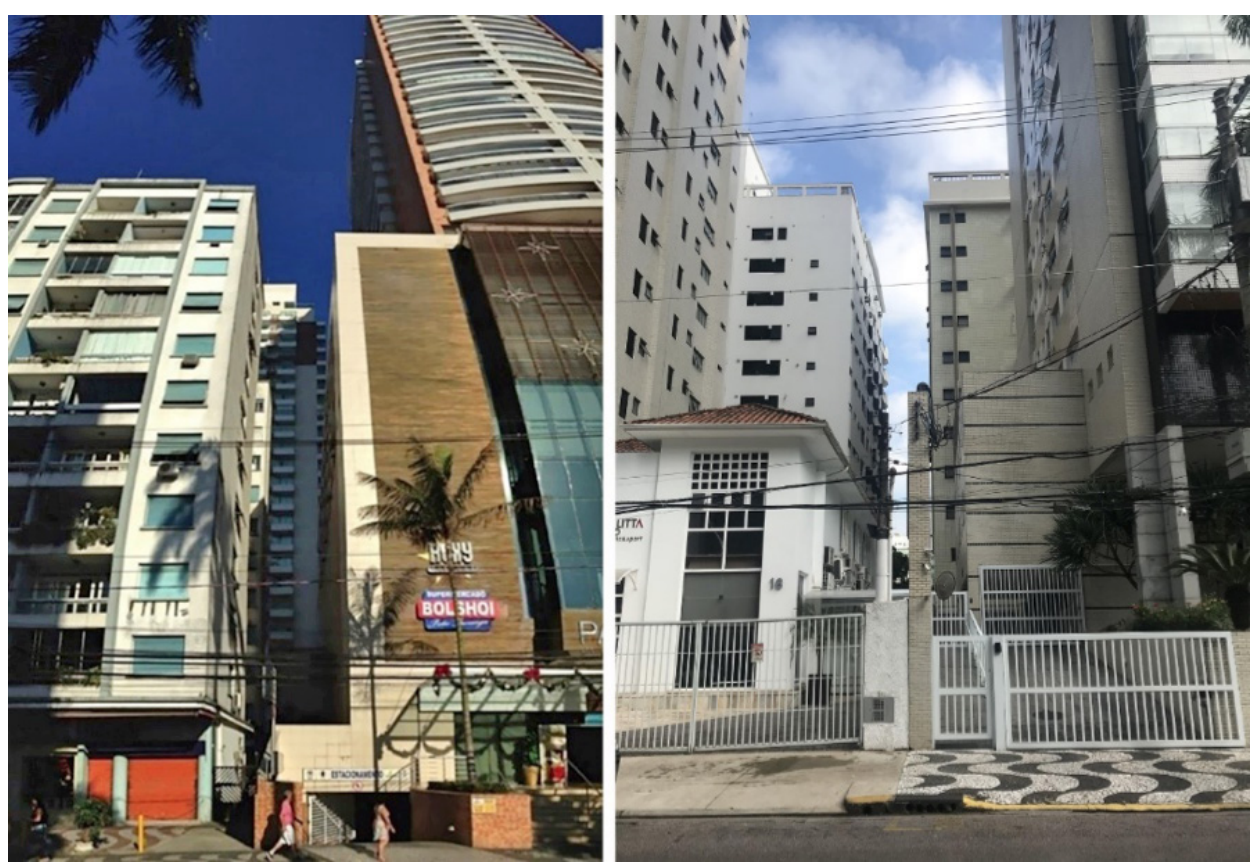
20 Esta altura varia de acordo com os sistemas estruturais adotados e espessura das lajes.
A norma anterior admitia até 4 pavimentos no embasamento, com pés-direitos máximos de 4,5 m (inciso II, $\S 3^{\circ}$, art. 35 ), podendo os dois primeiros pavimentos serem fundidos em um único, com até $7,5 \mathrm{~m}$ de pé-direito. Somava-se a este conjunto o afloramento do subsolo com 1,4 m de altura e platibanda sobre a laje do último pavimento, quando tivesse utilização. Se este pavimento tivesse piscina, o pé-direito poderia ser de 5,0 m, resultando em embasamentos com cerca de 19,0 m de altura. Com a nova norma, os embasamentos podem ter 5 pavimentos (inciso XXVI, art. $4^{\circ}$ ) e com piscina no último, seu pé-direito poderá ser de 5,5 m, ultrapassando $24,0 \mathrm{~m}$ de altura ${ }^{20}$, ampliando muito a altura do embasamento.

Mas como o mercado não adota pés-direitos altos no embasamento, devido ao aumento dos custos de construção, estes deverão ser mantidos em cerca de 3,0 m, com recuo igual a H/6, em embasamentos com 5 pavimentos, ultrapassando 19,0 $m$ de altura. Ainda assim, esta altura provocará externalizações indesejáveis, pois, na prática, a nova disciplina de recuos dos embasamentos assemelha-se à pior das quatro alternativas anteriormente oferecidas.

Somada à redução dos recuos, destaca-se na LC no 1.006/2018 a ampliação de incentivos à construção de terraços, terraços técnicos e varandas em balanço, pois esses elementos não são computados parcialmente no cálculo do CA e podem ser convertidos em extensões de cômodos, após a ocupação das edificações. Este incentivo é ainda maior, pois tolera-se balanço de varandas nos recuos lateral ( $\S 14$, art. 42) e frontal ( $\S 7^{\circ}$, art. 39), exceto no embasamento. No frontal, o balanço poderá ter até $4,0 \mathrm{~m}$, contra 2,50 $\mathrm{m}$ da lei anterior, quando o recuo frontal for igual ou superior a 10,0 m, o que só ocorre nas avenidas da orla da praia. Como as varandas são costumeiramente envidraçadas, configurando-se em extensões de cômodos, o recuo poderá cair para 6,0 m nessas vias, alterando critério utilizado desde 1896, com a Lei $n^{\circ} 82$, que fixou em $10,0 \mathrm{~m}$ os recuos frontais nessas avenidas.

Articulado à redução dos recuos, o aumento da TO máxima promovido em várias zonas afeta a relação com a vizinhança e cumulativamente pode provocar sobrecarga ao sistema público de drenagem.

Como se observa na Tabela 3, na LC n 730/2011, em quase todas as zonas, a TO era de $40 \%$, para o bloco dos pavimentos-tipo, sendo ampliada, pela LC $n^{\circ} 1.006 / 2018$, para $50 \%$ acima dos 4 primeiros pavimentos ou $60 \%$ em todo o edifício, em terrenos localizados na área de restrição de 45,0 m de altura, imposta pela portaria do COMAER, nas ZO e ZI.

Assim, outra vez utiliza-se como justificativa a restrição de altura da ZPA, a qual não afetaria o rendimento em termos de área comercializável, em empreendimentos com menos áreas comuns e vagas de automóveis, do tipo Habitação de Mercado Popular (HMP), que grosso modo correspondem às faixas superiores do Programa Minha Casa Minha Vida. Portanto, trata-se de benefício dirigido a uma demanda de padrão mais alto, a minoria da população, contrariando a intenção de incentivar a produção imobiliária na área central, exposta na justificativa da proposta (SANTOS, 2018), pois elevará ainda mais a atratividade da ZO e em partes da ZI onde não vigora a restrição de altura de 45,0 m. 
Para incentivar a produção residencial na área central seria necessário criar diferenciais como dispensa de oferta de número mínimo de vagas de automóveis e a redução das áreas comuns, além da estabelecida na LC n 1.006/2018, que só alcança a diminuta AAS-Norte. Ainda assim, somente seriam mais rentáveis empreendimentos na área de restrição do COMAER, se fosse diminuída a atratividade nas ZO e ZI. Portanto, a redução dos recuos, ampliação de varandas e ampliação da TO máxima não tornará a área central atrativa para o mercado imobiliário.

Também importante destacar o reduzido diferencial entre CAB e CAMáx nas AAS, igual a 1, com elevada TO de 70\%, até o $4^{\circ}$ pavimento do embasamento, contrariando os princípios de DOT, pois nessas áreas, embora haja dispensa de número mínimo de vagas em empreendimentos tipo HMP, não há limite para oferta destas. Portanto, o suposto incentivo a produção de HMP pode ser distorcido com adoção de embasamentos maiores, com oferta de muitas vagas, encarecendo as unidades.

É perniciosa a redução de recuos e ampliação da TO em áreas predominantemente residenciais com verticalização intensa, pois afeta o conforto ambiental e a eficiência energética e, portanto, amplia impactos ambientais e econômicos na vizinhança, podendo resultar em desvalorização imobiliária.

Tais impactos e externalidades distanciam o Município do que preconiza o Estatuto da Cidade, ao não adotar padrões de ocupação compatíveis com os limites da sustentabilidade ambiental do seu território, ao fixar índices urbanísticos que tendem a agravar problemas ambientais para as futuras gerações. Para garantir o direito ao desenvolvimento sustentável, é preciso tratar o desenvolvimento urbano como política pública, de modo a garantir à pessoa humana uma qualidade de vida digna (SAULE, 1997).

\section{Considerações finais}

Quanto ao pleno desenvolvimento das funções sociais da cidade e garantia do bem-estar de seus habitantes, a $L C n^{\circ} 1.006 / 2018$ significa retrocesso relativo à $L C n^{\circ} 730 / 2011$, que já havia apresentado poucos avanços ambientais em relação à LC n 312/1998.

Assim como o adensamento em vias saturadas e com problemas de alagamentos, sem perspectiva de implantação de transporte de média capacidade, a ampliação generalizada dos CA, sem o retorno de benefícios significativos para o desenho urbano ou para reinvestimento em áreas de urbanização inexistente ou incompleta, onde residem famílias de baixa renda, são aspectos que ferem diretamente o direito ao meio ambiente ecologicamente equilibrado. Igualmente nociva é a redução de recuos mínimos concomitante à ampliação generalizada da TO, em face dos prejuízos ambientais para a vizinhança e para o conjunto da cidade.

A nova norma amplia o potencial construtivo, sobretudo em áreas habitadas por famílias com renda mais alta, com previsíveis impactos ambientais deletérios, externalizações indesejáveis para a vizinhança e improváveis benefícios sociais, contendo contradições na regulação da ocupação do solo, impedindo o desenvolvimento urbano equitativo e prejudicando o direito à cidade sustentável. 
A LC 1.006/2018 prejudica o equilíbrio ambiental da cidade à medida que não se utiliza das diretrizes da politica urbana, para ordenar a ocupação do solo de modo a minimizar os efeitos negativos da urbanização. Portanto, é necessária a revisão da norma, antes que se cristalizarem situações que trarão mais prejuízos urbanísticos e ambientais.

\section{Referências bibliográficas}

ALFONSIN, B. O Estatudo da Cidade e a construção de cidades sustentáveis, justas e democráticas. In: Direito e Democracia, Revista de Ciências Jurídicas - ULBRA. Vol. 2. N. 2. 2001.

AMERICAN SOCIETY OF PLANNING OFFICIALS. Information Reportn. 111. Chicago: American Society of Planning Officials, 1958.

BARROS, M. F. de; CARRIÇO, J. M. 2019. Esvaziamento e transformação morfológica da área central de Santos/SP: gênese e perspectivas. Urbe. Revista Brasileira de Gestão Urbana, 11, e20180100. https://doi.org/10.1590/2175-3369.011.e20180100

BRASIL. Constituição (1988). Constituição da República Federativa do Brasil. Brasília, DF: Senado Federal: Centro Gráfico, 1988.

BRASIL (Aeronáutica). Portaria n 957/GC3, de 9 de julho de 2015. Dispõe sobre as restrições aos objetos projetados no espaço aéreo que possam afetar adversamente a segurança ou a regularidade das operações aéreas. Brasília: Diário Oficial da União, 17 jul. 2015.

Portaria DECEA $n^{\circ}$ 29//CA, de 14 de julho de 2015. Aprova o Plano Básico de Zona de Proteção de Aeródromo e o Plano de Zona de Proteção de Auxílios à Navegação Aérea para o Aeródromo Base Aérea de Santos. Brasília: Diário Oficial da União, 17 jul. 2015.

CARRIÇO, J. M. Afloramento do subsolo em Santos. A eliminação da interface entre espaço público e privado. Minha Cidade, 201.02, ano 17, abr. 2017. São Paulo: Arquitextos, 2017.

Produção do espaço urbano voltada às elites: doze anos de aplicação da Lei de Ordenamento do Uso e Ocupação do Solo na área insular de Santos. In Vazquez, D. A. (org.) A questão urbana na Baixada Santista. Santos: Leopoldianum, 2012. p. 145-176.

Legislação urbanística e segregação espacial nos municípios centrais da Região Metropolitana da Baixada Santista. 2002. Dissertação (mestrado em Estruturas Ambientais Urbanas) Faculdade de Arquitetura e Urbanismo, USP, São Paulo.

EMTU. Estudo Preliminar Pesquisa Mini OD Domiciliar. São Bernardo do Campo: EMTU; Consórcio Projetos SIM RMBS, 2013.

FARIAS, L. A. C. de. Mobilidade populacional e produção do espaço urbano na Baixada Santista: um olhar sociodemográfico sobre sua trajetória nos últimos 20 anos. Tese de Doutorado. Instituto de Filosofia e Ciências Humanas da Universidade Estadual de Campinas. 2018.

FREITAS, J. C. de. Ordem Urbanística e Acesso à Terra. In: ALFONSIN, B. FERNANDES, E. Direito à Moradia e Segurança da Posse no Estatuto da Cidade: Diretrizes, Instrumentos e Processo de Gestão. Belo Horizonte: Ed. Fórum. 2004 (p. 267).

IBGE. Censo Demográfico 2010. Resultados do Universo. Rio de Janeiro: IBGE, 2010.

MEYER, J. Adequação da Análise de Mercado Imobiliário: O caso de São Paulo. Tese (doutorado em Planejamento Urbano e Regional) Faculdade de Arquitetura e Urbanismo, USP, São Paulo, 2008.

PÉREZ, D. R. C.; FAVERO, E. O envelope solar como instrumento de regulamentação de acesso ao sol no espaço urbano e nas edificações: o caso de Campinas/SP, Brasil. In: XIII Seminario de Arquitectura Latinoamericana: Arquitectura y Clima, 2009, Clayton. v. 1. p. 1-3. 
PRATA, A. R. Impacto da altura dos edifícios nas condições de ventilação natural do meio urbano. Tese de doutorado. 2005. São Paulo: FAU USP.

PRESTES, V. B. Temas do Direito Urbano-Ambiental. Belo Horizonte/MG. Ed. Fórum, 2006.

SANTOS tem 26 projetos imobiliários em análise. A Tribuna de Santos. Santos, 15 set. 2019. Cidades, p. A4.

SANTOS (Município). Diagnóstico justificado da propositura. Santos: Prefeitura de Santos; Secretaria de Desenvolvimento Urbano, 2018. Disponível em: <https://www.santos.sp.gov. br/static/files_www/conteudo/luos_relatorio_tecnico.pdf>. Acesso em: 25 fev. 2020.

SAULE JR. N. Novas perspectivas do Direito Urbanístico brasileiro. Ordenamento constituciona da Política Urbana. Aplicação e eficácia do Plano Diretor. Porto Alegre/RS. Sergio Antônio Fabris Editor. 1997.

SECOVI-SP. Baixada Santista - Guarujá, Praia Grande, Santos e São Vicente - Economia e Demanda, principais indicadores. São Paulo: SECOVI-SP, 2019.

SILVA, J. A da. Direito Ambiental constitucional. $8^{\circ}$ ed. São Paulo/SP. Malheiros Editores, 2010.

SHOULP, D. Parking has dramatically shaped our cities (and not in a good way). [on line] Strong Towns, 25 jul. 2017. Disponível em: <https://www.strongtowns.org/journal/2017/7/24/ parking-has-shaped-our-cities>. Acesso em: 090set. 2019. 